\title{
MALUNITED SUPRACONDYLAR HUMERUS WITH CUBITUS VARUS DEFORMITY CORRECTED VIA LATERAL CLOSED WEDGE OSTEOTOMY AND FIXED WITH TENSION BAND WIRING AND WITH ADDITIONAL K WIRE FIXATION
}

\author{
Nagabhushan1, Shivaraj $B^{2}$, Shiva Kumar Bingi ${ }^{3}$
}

1 Professor, Department of Orthopaedics, JJMMC, Davangere, Karnataka, India.

2 Postgraduate Student, Department of Orthopaedics, JJMMC, Davangere, Karnataka, India.

${ }_{3}^{3}$ Postgraduate Student, Department of Orthopaedics, JJMMC, Davangere, Karnataka, India.

HOW TO CITE THIS ARTICLE: Nagabhushan, Shivaraj B, Bingi SK. Malunited supracondylar humerus with cubitus varus deformity corrected via lateral closed wedge osteotomy and fixed with tension band wiring and with additional K wire fixation. J. Evolution Med. Dent. Sci. 2019;8(10):751-753, DOI: 10.14260/jemds/2019/165

\section{PRESENTATION OF CASE}

A 12 yrs. old boy was brought to our hospital on $11^{\text {th }}$ January 2017 with the chief complaints of deformity and restricted movements of left elbow since 1 year six months. Patient gives a history of fall on outstretched hand while playing 1 and $1 / 2$ years back on January 11th 2017 following trauma patient was taken to local bone setter where bandage was applied after massaging for a total of 3 times over a span of 1 month and after the bandage was removed patient noticed he had restriction of movements and deformity over the left elbow. He did not take any medical advise for the same and now after 1 and half years presented to us with the above mentioned complaints. Patients also gives history of fall previously on $2^{\text {nd }}$ Feb. 2015 for which he again went to local bone setter and bandage was applied for 14 days and later patient was symptom free until the second trauma.

On examination, patient had reduced carrying angle (cubitus varus deformity) of left elbow associated with internal rotation of left forearm. Medial and lateral supracondylar ridges were thickened. The 3 bony point relationship was not altered, elbow range of motion was reduced with flexion only until 90 degrees, there was no limb length discrepancy and distal neurovascular status was intact. Range of movements of ipsilateral shoulder and wrist were within normal limits. AP and LATERAL views of $\mathrm{x}$-ray of left elbow was done. X-ray was reported as malunited supracondylar humerus fracture.

After counselling the patient and after obtaining written consent, surgical intervention was done under general anaesthesia. Lateral closed wedge osteotomy procedure was done with additional $2 \mathrm{k}$-wires was inserted and A/E pop slab was applied and post operatively patient had no complications and sutures were removed on the 10th day.

'Financial or Other Competing Interest': None.

Submission 13-12-2018, Peer Review 18-02-2019,

Acceptance 25-02-2019, Published 11-03-2019.

Corresponding Author:

Dr. Shivaraj $B$,

2005/2, Ashirwad Building,

$15^{\text {th }}$ Cross,

Anjinaya Badavane,

Davanagere, Karnataka,

India.

E-mail: shivarajrox@gmail.com

DOI: $10.14260 /$ jemds $/ 2019 / 165$

\section{(c) $(1) \ominus$}

Patient was clinic-radiologically followed up regularly at 2 weeks interval. At 6 weeks pop and k-wires were removed and patient was put on ROM under supervision of physiotherapists.

\section{DIFFERENTIAL DIAGNOSIS}

In children, malunited supracondylar humerus fracture, medial epicondyle fracture, lateral epicondyle fracture, Physeal injury of distal humerus.

\section{CLINICAL DIAGNOSIS}

Left sided cubitus varus deformity secondary to malunited supracondylar humerus fracture with carrying angle of -20 degree without distal neurovascular injury
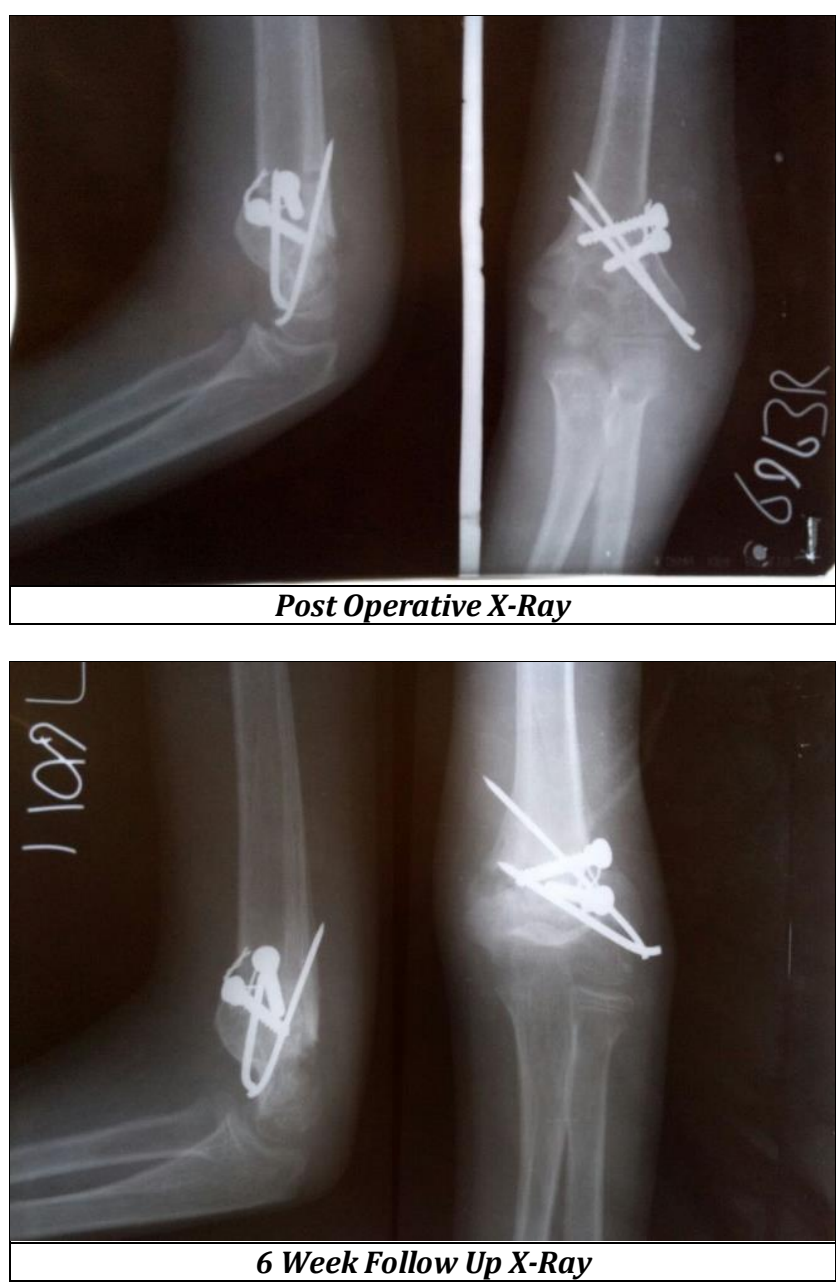

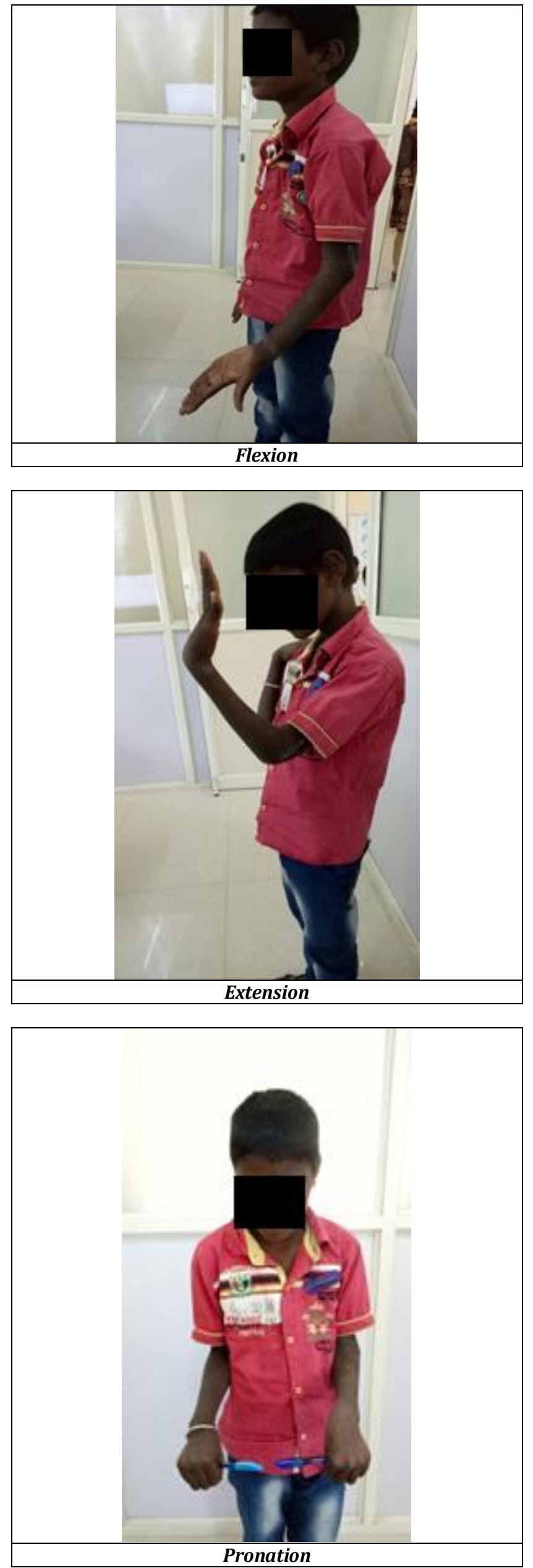

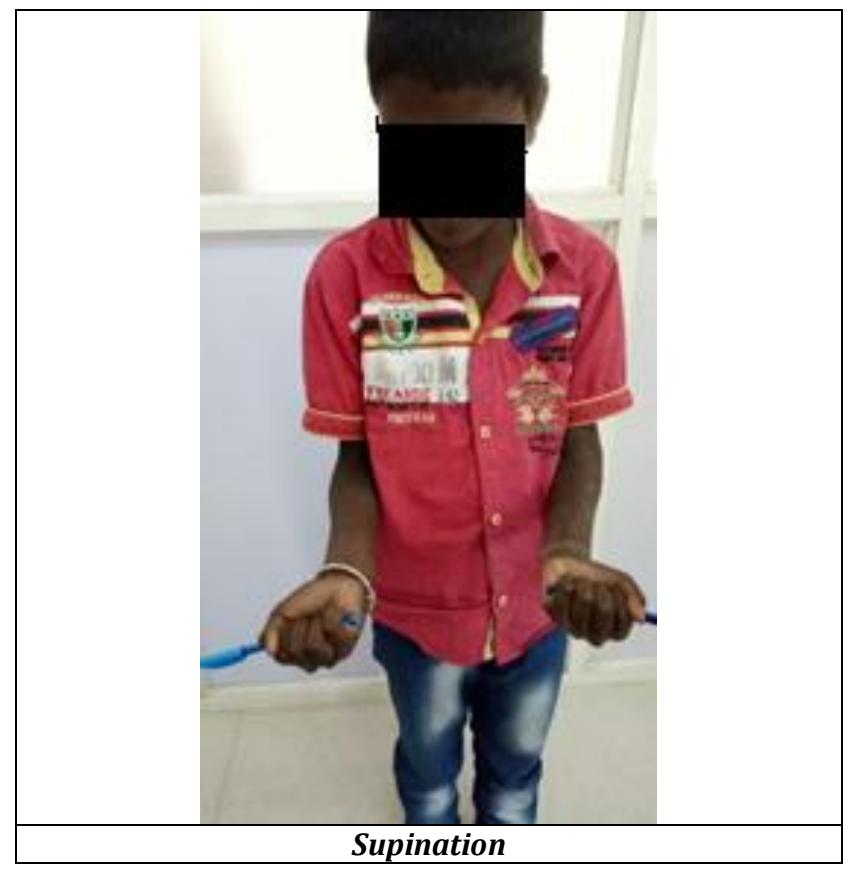

\section{DISCUSSION MANAGEMENT}

Cubitus varus deformity is one of the most common complications seen in paediatric patients (age group: 5-8 years) following trauma. $(1,2,3)$ cubitus varus can increase the risk of lateral condylar fracture, pain, tardy posterolateral rotatory instability, internal rotational malalignment and poor cosmesis.

In supracondylar humerus fracture types I and II has enough residual internal stability and are treated with cast or posterior splint. $(4,5,6,7,8)$ and results are satisfactory. In older children's displacement of fracture is more results are unsatisfactory as compared with young children. In displaced fractures open reduction and internal fixation with 2 smooth $\mathrm{k}$-wires is the modality of treatment. $(9,10,11,12) 2 \mathrm{k}$-wires are necessary because of the sagittal rotation forces exerted on the fracture fragment by the common flexor muscles.

For cubitus varus deformity various osteotomies have been described as corrective surgeries like lateral closed wedge osteotomy, medial open wedge osteotomy, dome osteotomy, step-cut osteotomy, oblique osteotomy with derotation. In our study lateral closed wedge osteotomy was a choice of treatment.

Lateral closed wedge osteotomy was performed above the olecranon fossa at diaphysiometaphyseal junction. With fluoroscopic guidance 2 screws of $4.5 \mathrm{~mm}$ were inserted into lateral condyle before osteotomy. Closing wedge osteotomy was made laterally leaving medial cortex intact, which was weekend with drill holes. A forceful valgus stress was applied to complete the osteotomy with forearm in pronation and flexed elbow. Tension band wiring was done to achieve a compression. Additionally, 2 smooth k-wires from lateral condyle to medial condyle to the proximal fragment was inserted for additional stability. The wires were buried under the skin. After closure of wound posterior above elbow slab was applied in 90 degree with forearm in pronation.

\section{FINAL DIAGNOSIS}

Clinicoradiologically, it was a case of left side cubitus varus deformity with carrying angle of -20 degree with restricted elbow flexion without neurovascular deficit. 


\section{REFERENCES}

[1] Smith L. Deformity following supracondylar fractures of the humerus. J Bone Joint Surg Am 1965;47(8):1668.

[2] Theruvil B, Kapoor V, Fairhurst J, et al. Progressive cubitus varus due to a bony physeal bar in a 4 year old girl following a supracondylar fracture: a case report. J Orthop Trauma 2005;19(9):669-72.

[3] French PR. Varus deformity of the elbow following supracondylar fractures of the humerus in children. Lancet 1959;2(7100):439-41.

[4] Faysse R, Marion J. Fractures du condyle interne. Rev Chir Orthop 1962;48:473-7.

[5] Papavasiliou V, Nenopoulos S, Venturis T. Fractures of the medial condyle of the humerus in childhood. J Pediatr Orthop 1987;7(4):421-3.

[6] Bensahel H, Csukonyi Z, Badelon O, et al. Fractures of the medial condyle of the humerus in children. J Pediatr Orthop 1986;6(4):430-3.

[7] Glotzbecker MP, Bae DS, Links AC, et al. Fishtail deformity of the distal humerus: a report of 15 cases. J Pediatr Orthop 2013;33(6):592-7.
[8] Kim HT, Song MB, Conjares JN, et al. Trochlear deformity occurring after distal humeral fractures: magnetic resonance imaging and its natural progression. J Pediatr Orthop 2002;22(2):188-93.

[9] Case SL, Hennrikus WL. Surgical treatment of displaced medial epicondyle fractures in adolescent athletes. Am J Sports Med 1997;25(5):682-6.

[10] Fowles JV, Kassab MT. Displaced fractures of the medial humeral condyle in children. J Bone Joint Surg Am 1980;62(7):1159-63.

[11] Kilfoyle RM. Fractures of the medial condyle and epicondyle of the elbow in children. Clin Orthop Relat Res 1965;41:43-50.

[12] Pimpalnerkar AL, Balasubramaniam G, Young SK, et al. Type four fracture of the medial epicondyle: a true indication for surgical intervention. Injury 1998;29(10):751-6. 